\title{
Experimental Evaluation and Numerical Modelling Residual Stresses in Glass Panel
}

\author{
Jüri Majak $^{1, a}$, Johan Anton ${ }^{3,4}$, Erko Õunapuu ${ }^{1}$, Fabio Auriemma ${ }^{1}$, Meelis Pohlak ${ }^{1}$, Martin Eerme ${ }^{1}$ and \\ Aleksander Klauson ${ }^{2}$ \\ ${ }^{1}$ Department of Mechanical and Industrial Engineering, Tallinn University of Technology, 19086, Tallinn, Estonia \\ ${ }^{2}$ Department of Civil Engineering and Architecture, Tallinn University of Technology, 19086, Tallinn, Estonia \\ ${ }^{3}$ Department of Cybernetics, Tallinn University of Technology, 19086, Tallinn, Estonia \\ ${ }^{4}$ GlasStress Ltd, 12618, Tallinn, Estonia
}

\begin{abstract}
During last decade increased usage of laminated composite glass structures, also annealed and tempered glass can be observed in civil engineering, automobile and space structures, solar panels, etc. Latter trend is caused by high strength properties of laminated glass, also sound and vibration attenuation capabilities. However, heat treatment of glass causes residual stresses, which are not often covered in structural analysis. Current study is focused on experimental evaluation and numerical modelling of residual stresses in glass panels.
\end{abstract}

\section{Introduction}

The non-destructive testing methods are preferred as resource saving and sustainable. The PVB interlayers have key role in aging of LGCP laminates and need special attention since in a number of application long term exploitation of LGCP panels has been foreseen (solar panels, windows). The elastic material properties of the PVB interlayer determined experimentally are used as simulation input parameters in order to predict vibration attenuation capability at concurrent frequency excitation and displacement.

The main advantage of the laminated glass composite panel, over float glass is its high strength properties, especially fact that it does not break into small pieces even in the case of impact loading cases [1]. The residual stresses arise in glass during cooling down from the crystallization temperature. The residual stresses are caused by the thermal expansion and the elastic mismatch between the crystalline and glassy phases [2,3]. The strengthening effect is achieved with accurate cooling the glass after heat treatment. The fast cooling causes outer layers of the glass to compress and close micro cracks in the surface of the glass. The heat treated glass is used in applications with safety glass requirements [4]. The heat treated glass, especially laminated glass composite panels (LGCP) are used in structures where glass is the main load bearing element. The LGCP consists of glass layers and at least one flexible interlayer. The interlayer provides higher post failure safety of LGCP due to ability to hold broken-off pieces of glass together [5]. Multifunctional LGCP with improved strength and acoustic performance can be obtained by using novel acoustic interlayers covering strengthening and

\footnotetext{
${ }^{\text {a }}$ Corresponding author : juri.majak@taltech.ee
} 
sound attenuation properties simultaneously. Development of new sound absorptive element for wide class of structures and applications is emerging research area [6-9].

In the current study an attempt is made to combine the know-how and capabilities of the private company GlasStress Ltd in area of experimental study of residual stresses in glass structures [10-12] and optimization workgroup of TTU (Tallinn University of Technology) in area of structural analysis and design optimization [13-17].

\section{Experimental study}

The experimental study performed cover evaluation of residual stresses in glass, also measuring the properties of the constituents of glass laminate composite panel for use in further numerical analysis.

\subsection{Residual stresses in glass}

\subsubsection{Measuring residual stresses}

Measuring residual stresses has been conducted in private company GlasStress Ltd according to proposed design of experiment. The SCALP-05 and scattered light method were used to determine through-the-thickness stress distribution of annealed and heat treated sodalime glass panels. Three repeatable measurements were done in directions of the long and short sides of the panel at 10 different locations panel. The residual stresses were measured on both sides up to middle surface of the glass panel. The tin side of the glass was detected by employing Tin Side Detector UV1301. The samples tested were $500 \times 200 \mathrm{~mm}$ with thicknesses: $4 \mathrm{~mm}, 8 \mathrm{~mm}$ and $4+4 \mathrm{~mm}$ laminated glass with $0,38 \mathrm{~mm}$ PVB interlayer. Through-thickness distribution of the stress component $\sigma_{\mathbf{1}}$ is given in Figure 1.

$8 \mathrm{~mm}$

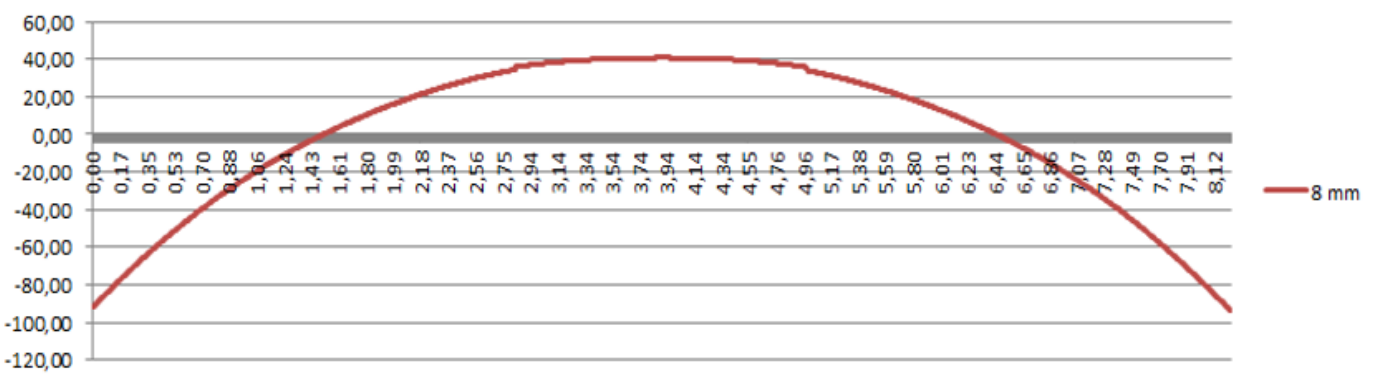

Figure 1. Normal stress component $\sigma_{\mathbf{1}}$ - through-thickness distribution

Similarly, symmetric through-thickness distribution of the normal stress component $\sigma_{2}$ has been observed. The experimental data obtained, provide valuable information on behaviour of residual stresses in glass panel. However, these data are not enough for numerical modelling of residual stresses in glass panel due to presence of normal stress components only. Solution of the latter problem is discussed in the following section.

\subsubsection{Determining shear stresses in laminated glass}

In order to evaluate the shear stresses $\sigma_{12}$ in glass panel the procedure based on measurement of normal stresses in different rotation angles and application of the plane stress tensor rotation formulas is introduced. The procedure is given as follows:

- The initial coordinate system was specified by long and short sides of the glass specimen;

- The stress components $\sigma_{1}^{\text {exp_o }}$ and $\sigma_{2}^{\text {exp_o }}{ }^{2}$ were measured in coordinate system rotated $0^{\circ}$; 
- The stress components $\sigma_{1}^{\exp \_} \theta$ and $\sigma_{2}^{\exp \theta_{-}}$were measured in coordinate system rotated $\theta^{\circ}$;

- Based on values of the stress components $\sigma_{1}^{\text {exp_o }}$ and $\sigma_{2}^{\text {exp_o }}$ the theoretical expected values of the stress components in coordinate system rotated $\theta^{\circ}$ were computed by employing stress tensor rotation formulas as

$$
\begin{aligned}
& \sigma_{1}^{\text {theoret } \theta}=\sigma_{1}^{\text {exp_0}} \cos ^{2}(\theta)+\sigma_{2}^{\text {exp_o }} \sin ^{2}(\theta)+2 \sigma_{12}^{0} \sin (\theta) \cos (\theta), \\
& \sigma_{2}^{\text {theoret } \_} \theta=\sigma_{1}^{\text {exp } \_0} \sin ^{2}(\theta)+\sigma_{2}^{\text {exp_0}} \cos ^{2}(\theta)-2 \sigma_{12}^{0} \sin (\theta) \cos (\theta),
\end{aligned}
$$

- Note that the formulas (1)-(2) are not directly applicable, since the value of the shear stress $\sigma_{12}^{0}$ is unknown. For this reason the shear stress $\sigma_{12}^{0}$ was considered as design variable and the differences between experimentally measured normal stresses $\sigma_{1}^{\exp _{-} \theta}, \sigma_{2}^{\exp _{-} \theta}$ and theoretically computed normal stresses $\sigma_{1}^{\text {theoret }} \theta, \sigma_{2}^{\text {theoret_}} \theta$ were subjected to minimization

$$
f=\left(\sigma_{1}^{\text {theoret }} \theta-\sigma_{1}^{\exp _{-} \theta}\right)^{2}+\left(\sigma_{2}^{\text {theoret }}{ }_{-} \theta-\sigma_{2}^{\exp _{-} \theta}\right)^{2} \rightarrow \text { min. }
$$

- Applying the necessary optimality conditions for posed optimization problem $\frac{\partial f}{\partial \sigma_{12}^{0}}=0$, the value of the shear stress $\sigma_{12}^{0}$ in initial coordinate system was determined as

$$
\sigma_{12}^{0}=\frac{\left(\sin ^{2}(\theta)-\cos ^{2}(\theta)\right)\left(\sigma_{1}^{\exp _{-} 0}-\sigma_{2}^{\exp _{-} 0}\right)+\left(\sigma_{1}^{\exp _{-} \theta}-\sigma_{2}^{\exp _{-} \theta}\right)}{4 \sin (\theta) \cos (\theta)} .
$$

Note, that the proposed approach is based on measuring residual stresses in two different angles of the coordinate system and is just one possibility for estimating the value of the shear stress $\sigma_{12}^{0}$. Obviously, the result depends on selection the value of the rotation angle $\theta$. The theoretical approach introduced can be simply extended for a number of rotations of the stress tensor by angles $\theta_{1}$ to $\theta_{n}$. However, in latter case the cost needed to pay for higher accuracy is higher number of experiments (the normal stresses should be measured for each value of $\theta_{i}$ ).

\subsubsection{Error estimate}

Having the measured values of the normal stresses $\sigma_{1}^{\exp { }_{-} 0}, \sigma_{2}^{\exp { }_{-} 0}$ in initial coordinate system and corresponding estimate on shear stress $\sigma_{12}^{0}$ one can apply the stress tensor rotation formulas (1)-(2) for computing the theoretical values of normal stresses $\sigma_{1}^{\text {theoret }} \theta$ and $\sigma_{2}^{\text {theoret_}} \theta$ in new, rotated coordinate system. The errors $e_{1}$ and $e_{2}$ of the measured normal stresses $\sigma_{1}$ and $\sigma_{2}$ can be estimated as

$$
\begin{aligned}
& e_{1}=\sigma_{1}^{\text {exp }} \theta-\sigma_{1}^{\text {theoret }} \theta, \\
& e_{2}=\sigma_{2}^{\text {exp}_{-} \theta}-\sigma_{2}^{\text {theoret }} \theta \text {. }
\end{aligned}
$$

It should be noted that $e_{1}$ and $e_{2}$ are caused by measuring errors in both coordinate systems (initial and rotated by angle $\theta$ ). Based on formulas (5)-(6) the error of residual stresses near outer surface (biggest values of stresses) are estimated $\sim 1 \mathrm{MPa}$ (near $1 \%$ ).

\subsection{Properties of glass layer - non-destructive testing}

In order to perform numerical analysis of glass panel the mechanical properties of the panel should be determined. However, performing traditional mechanical tests with glass specimen is rather complicated, especially tension tests, etc. Furthermore, as mentioned above the non-destructive testing should be preferred. The non-destructive mechanical testing procedure for glass panel was introduced by authors in [18]. The time of flight of the individual pulses has been measured in order to determine sound speeds of P-wave and shear wave. The setup of the test is shown in Figure 2. 


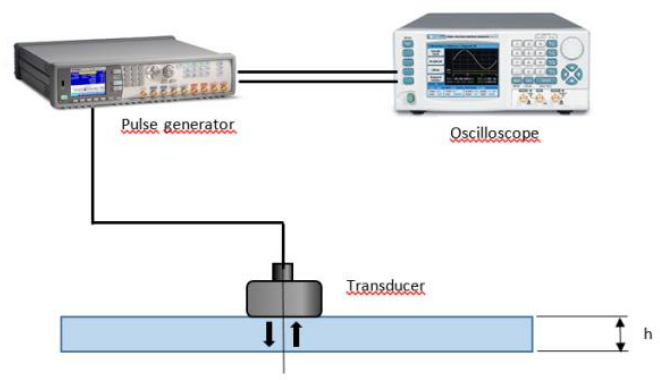

Figure 2. Set up for measuring P-wave and shear wave speeds

The Young modulus and Poisson ratio of the glass can be evaluated as

where

$$
\begin{gathered}
E=\frac{G(3 M-4 G)}{M-G}, \\
v=\frac{M-2 G}{2 M-2 G},
\end{gathered}
$$

$$
M=c_{P}^{2} \rho, \quad G=c_{s}^{2} \rho,
$$

$c_{P}$ and $c_{s}$ stand for the wave speeds and $\rho$ is a material density. The wave speeds measured as well as the material properties computed are presented in table 1.

Table 1. Material properties of the glass layer.

\begin{tabular}{|l|c|c|c|c|c|}
\hline & $\begin{array}{c}\rho \\
\left(\mathrm{kg} / \mathrm{m}^{3}\right)\end{array}$ & $\begin{array}{c}c_{P} \\
(\mathrm{~m} / \mathrm{s})\end{array}$ & $\begin{array}{c}c_{s} \\
(\mathrm{~m} / \mathrm{s})\end{array}$ & $\begin{array}{c}\mathrm{E} \\
(\mathrm{GPa})\end{array}$ & $v$ \\
\hline Float glass & 2486 & 5914 & 3506 & 75.11 & 0.23 \\
\hline Tempered glass & 2486 & 5852 & 3433 & 72.53 & 0.24 \\
\hline
\end{tabular}

The mechanical properties of the PVB interlayer are determined from traditional tensile tests. Due to small thickness and viscoelastic material properties of PVB interlayer the above proposed nondestructive testing is complicated.

\section{Numerical modelling}

The experimental data acquired by employing procedures introduced in sections 2.1 and 2.2 can be utilized as input data for finite element method (FEM) analysis model. The FE analysis was performed using ANSYS v14.

\subsection{FEM model and its validation tests}

Modal analysis of glass panels without supports and pre-stress was selected for FE model development and validation. FEA model consists of 50000 8-noded hexahedral 3D solid elements (8 layers of elements through the thickness of the glass sheet). The FEA and experimental modal analysis has been applied to a glass panel with dimensions $500 \mathrm{~mm} \times 200 \mathrm{~mm} \times 8 \mathrm{~mm}$. The samples are held by a suspension system, constituted by soft elastic bands. These bands are designed to guarantee that the highest rigid mode frequency is less than $10-15 \%$ of the first resonance frequency of the suspended structure. This circumstance allows considering the systems as in free-free conditions. The classical roving hammer impact test has been used to measure the frequency response functions and to implement the peak-picking method. Preliminarily, a set of points are defined on a wire-frame created on the structure and an accelerometer is fixed on one of these points. The method consists of 
measuring the frequency response functions between the response measured by the accelerometer and the forced excitation provided by the hammer when the wire-frame points are sequentially hit. In the present investigation, the samples have been schematized with a wire-frame consisting of 12 points displaced in adjacent rectangular patterns. An impulsive excitation has been provided, along the direction perpendicular to the plane of the structure, by means of a hammer AP TechTM AU01 provided with force transducer. The vibration response has been measured, along the same direction, by means of an ICP (Integrated Circuit Piezoelectric) mono- axial accelerometer PCB TM 353B33. The signal acquisition has been performed by a dynamic signal analyser (National Instruments TM NIcDAQ 9174 and NI 9234), controlled by PC based virtual instrument (LabVIEW TM). Random errors have been reduced by averaging out three subsequent measurements taken for each point. The frequency response functions have been estimated as $\mathrm{H}=\mathrm{SXY} / \mathrm{SXX}$, i.e. as the ratio of the crossspectrum of excitation and response signals over the auto-spectrum of the excitation signal (Figure 3).

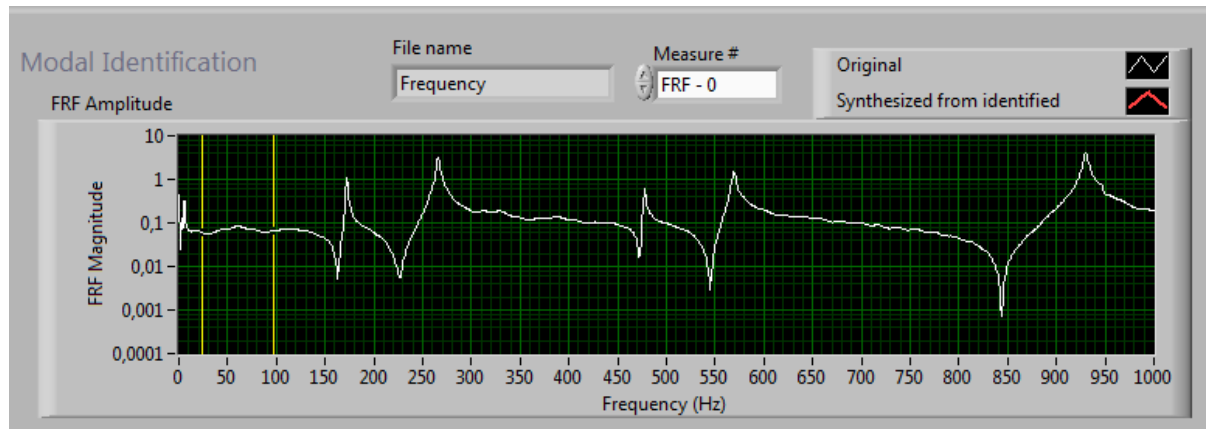

Figure 3. FRF Magnitude vs frequency.

The values of the coherence function related to the impact tests, are above $98 \%$, indicating low levels of uncorrelated noise in the measured frequency response data. In Table 2 the values of the natural frequencies obtained from FEM analysis and experimental tests are presented.

Table 2. Frequency values. FEM vs experimental.

\begin{tabular}{|c|c|c|}
\hline Mode & $\begin{array}{c}\text { Frequency, Hz } \\
\text { FEM model }\end{array}$ & $\begin{array}{c}\text { Frequency, Hz } \\
\text { Experimental }\end{array}$ \\
\hline 1 & 172 & 172 \\
\hline 2 & 267 & 266 \\
\hline 3 & 477 & 477 \\
\hline 4 & 571 & 569 \\
\hline 5 & 930 & 930 \\
\hline
\end{tabular}

One can be observed from Table 2 that the results obtained from experimental study and FEM analysis are in good agreement.

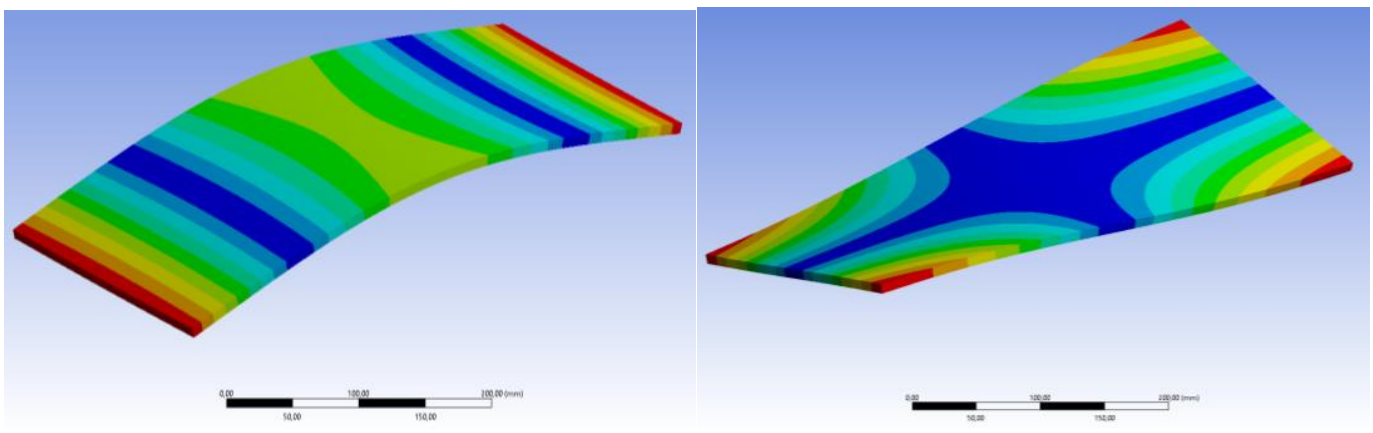

Figure 4. Fundamental frequency and second harmonic.

The fundamental frequency and second harmonic are depicted in Figure 4. 


\subsection{Modelling residual stresses in glass}

Glass panel with size $200 \times 500 \times 8 \mathrm{~mm}$ and material properties described above was considered. In order to apply pre-stress one side of panel was fixed (short side is fixed) i.e. console. The values of the stress tensor obtained from experimental study (normal stresses $\sigma_{1}$ and $\sigma_{2}$ ) and from procedure proposed in section 2.1.2 (shear stress $\sigma_{12}$ ) are mapped into FEA model by ANSYS throughout the thickness in 57834 points (Figure 5).

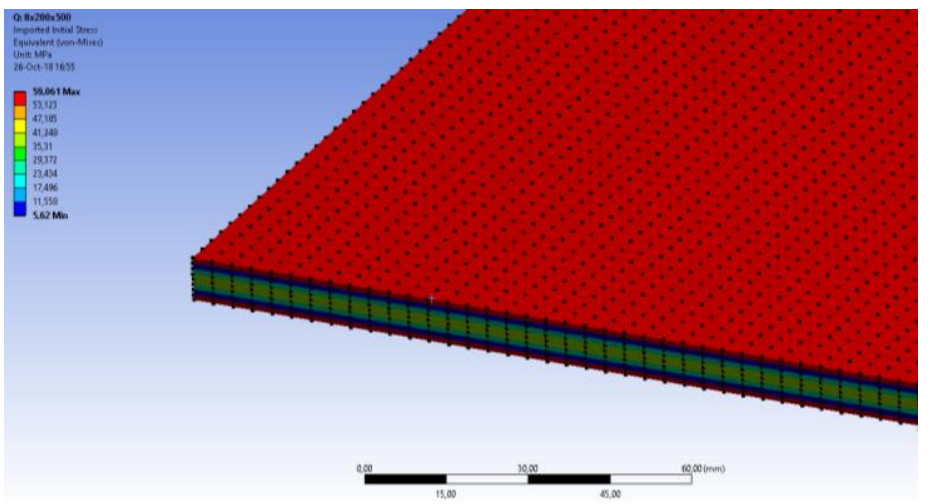

Figure 5. Mapped stresses.

The results of modal analysis are given in Table 3.

Table 3. Frequency values, with and without pre-stress

\begin{tabular}{|c|c|c|}
\hline Mode & $\begin{array}{c}\text { Frequency, Hz } \\
\text { without pre-stress }\end{array}$ & $\begin{array}{c}\text { Frequency, Hz } \\
\text { with pre-stress }\end{array}$ \\
\hline 1 & 27 & 28 \\
\hline 2 & 145 & 150 \\
\hline 3 & 171 & 174 \\
\hline 4 & 461 & 476 \\
\hline 5 & 480 & 489 \\
\hline
\end{tabular}

In can be observed from Table 3 that in the case of considered boundary conditions (console type, short side fixed) the influence of residual stresses on frequency values is remarkable. Application of residual stresses increase the values of the frequencies. The modes corresponding to first two frequencies are depicted in Figure 6.

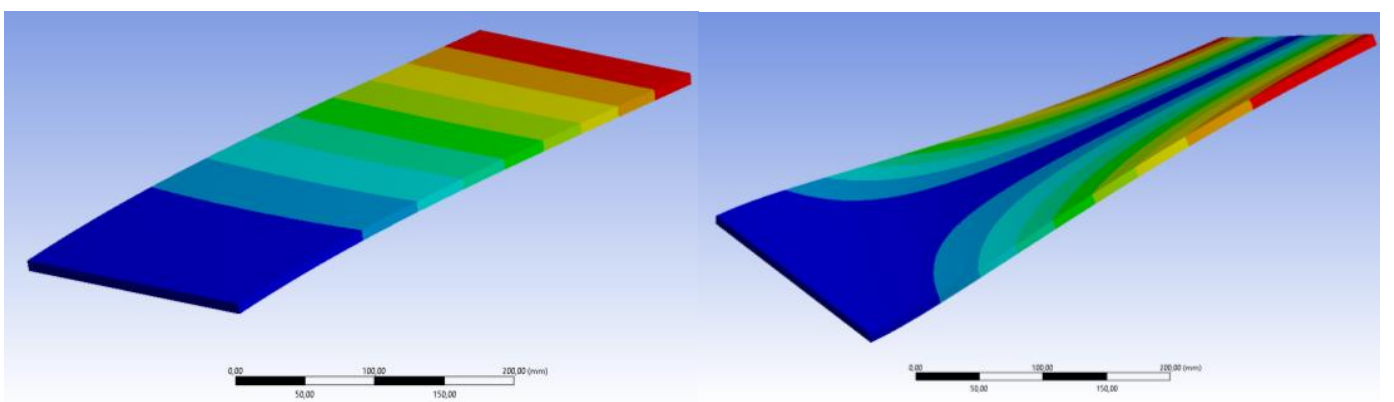

Figure 6. Fundamental frequency and second harmonic for pre-stressed panel. fixed.

Figure 6 is obtained by applying console type boundary conditions where short side of the panel is

\section{Conclusions}


An approach for structural analysis the glass panels, incorporating residual stresses, has been proposed. The normal residual stresses were determined experimentally in private company GlasStress Ltd. The procedure for determining shear stress component of residual stress tensor has been developed. The algorithm for estimating error of the measured residual stresses has been introduced. The finite element model incorporating residual stresses has been developed. The remarkable influence of the residual stresses on values of the natural frequencies has been observed. An approach proposed for structural analysis can be applied for wide class of glass structures. Future study planned cover design optimization of laminated glass composite panel [19-23].

\section{Acknowledgments}

The authors acknowledge Innovative Manufacturing Engineering Systems Competence Centre IMECC (co-financed by the project EU48685); the Estonian Centre of Excellence in Zero Energy and Resource Efficient Smart Buildings and Districts, ZEBE, TK146 funded by the European Regional Development Fund (grant 2014-2020.4.01.15-0016); Estonian Research Council grant PUT1300.

\section{References}

1. M. Haldimann, A. Luible A and M. Overend, Structural Engineering Documents, 10. IABSE, Zürich (2008).

2. M. Kotoul, J. Pokluda, P. Sandera, I. Dlouh?, Z. Chlup, A.R. Boccaccini, Acta Mater., 56, 29082918 (2008).

3. F.C. Serbena, E.D. Zanotto, Journal of Non-Crystalline Solids, 358, 6-7, 975-984 (2012).

4. M. Fröling, Strength Design Methods for Glass Structures, Doctoral Thesis (2013).

5. X. Zhang H. Hao, Construction and Building Materials, 93, 404-415 (2015).

6. F. Auriemma, H. Rammal, J. Lavrentiev, SAE Int. J. of Materials and Manufacturing, 1,1, 600611 (2014).

7. F. Auriemma, Applied Acoustics,122, 128-137 (2017).

8. F. Auriemma, Acoustics Australia, 45, 2, 411-419 (2017).

9. F. Auriemma, Proc. of Meetings on Acoustics Meeting of Acoust. Society of America, 30, 1 (2017).

10. S. Hödemann, A. Valdmann, J. Anton, T. Murata, J. of Materials Sci., 51,12 (2016).

11. H. Aben, J. Anton, M. Õis, K. Viswanathan, C. Chandrasekar, M. M. Chaudhri, App. Physics Letters, 109, 231903 (2016).

12. H. Aben, D. Lochegnies, Y. Chen, J. Anton, M. Paemurru, M. Õis, Experim. Mech., 55, 2, 483486 (2015).

13. J. Lellep, J. Majak, Struct. Optimization, 14, 116-120 (1997).

14. J. Lellep, J. Majak, Mech. of Composite Materials, 36, 4, 261-266 (2000).

15. A. Aruniit, J. Kers, J. Majak, A. Krumme, K. Tall, Proc. of Estonian Acad. of Sci., 61, 3, 160-165 (2012).

16. A. Aruniit, J. Kers, D. Goljandin, M. Saarna, K. Tall, J. Majak, H. Herranen, Materials Science (Medžiagotyra), 17, 3, 276-281 (2011).

17. J.Majak, S.Hannus, Mech. of Composite Materials, 39, 6, 509-520 (2003).

18. K.Väer, J. Anton, A. Klauson, M. Eerme, E. Õunapuu, P. Tšukrejev, Journal of Achievements in Materials and Manufacturing Engineering, 81,1, 11-17 (2017).

19. J. Šliseris, K. Rocens, World Acad. of Sci., Eng. and Tech., 76, 317-323 (2011).

20. J. Šliseris, K. Rocens, J. of Civil Eng. and Management, 19 (5), 696-704 (2013).

21. W.H.Zhang, M. Domaszewski, D. Bassir, Structural Optimization, 17, 2, 219-225 (1999).

22. S. Guessasma, D. Bassir, L. Hedjazi, Materials and Design, 65, 1053-1063 (2015).

23. J.Zhu, W. Zhang, L. Xia, Q. Zhang, D. Bassir, Journal of Intelligent and Robotic Systems: Theory and Applications. 67, 3-4, 185-199 (2012). 